\title{
Rhegmatogenous retinal detachments associated to Stickler syndrome in a tertiary eye care center in Saudi Arabia
}

This article was published in the following Dove Press journal:

Clinical Ophthalmology

21 December 2015

Number of times this article has been viewed

\author{
Saeed T Alshahrani' \\ Nicola G Ghazi ${ }^{2}$ \\ Saba Al-Rashaed ${ }^{2}$ \\ 'Ophthalmology Department, King \\ Fahad Specialist Hospital, Dammam, \\ ${ }^{2}$ Vitreoretinal Department, King \\ Khaled Eye Specialist Hospital, Riyadh, \\ Kingdom of Saudi Arabia
}

Purpose: To investigate the clinical findings and outcomes of rhegmatogenous retinal detachment (RRD) in Stickler syndrome on affected and fellow eyes that underwent prophylactic retinopexy.

Patients and methods: Chart review of 70 eyes (62 patients). Incidence of RRD, postoperative visual acuity, and risk factors were evaluated.

Results: Twenty-two patients (35\%) had RRD in the fellow eye, $37 \%$ of the eyes had cataract, 93\% had macular detachment, $50 \%$ had proliferative vitreoretinopathy, and $41 \%$ had posterior vitreous detachment. Success rates were: $60 \%$ of patients after scleral buckling; $57.1 \%$ after pars plana vitrectomy; and $75 \%$ after combined scleral buckling and pars plana vitrectomy. Sixty-one (93.8\%) of patients had successful surgery (including second surgery). Silicone oil tamponade was significantly associated with final anatomic outcome, with a protective odds ratio of $0.11(P=0.027)$. Visual acuity improved in $54 \%$ of eyes and decreased in $5 \%$. Statistically significant associations were present for eyes with final visual acuity $\geq 20 / 200$, and total retinal detachment $(P<0.001)$; preoperative cataract $(P=0.023)$; and proliferative vitreoretinopathy $(P<0.001)$. RRD developed in 16/44 eyes despite laser prophylaxis.

Conclusion: Prophylactic retinopexy was not beneficial for Stickler syndrome patients. Success of primary surgery for RRD remains low. The primary surgery should be vitrectomy combined with scleral buckling and silicone oil tamponade.

Keywords: Stickler syndrome, retinopexy, Gulf States, Saudi Arabia, ocular genetics, arthroophthalmopathy, collagen disorder

\section{Introduction}

Stickler syndrome was originally described in 1965 as an autosomal-dominant arthro-ophthalmopathy with predominant ophthalmic, orofacial, auditory, and articular manifestations. ${ }^{1}$ It is a collagen disorder of the connective tissue and is the most common disorder of hereditary vitreous abnormalities with an incidence of $\sim 1: 10,000$ births. ${ }^{2,3}$ Stickler syndrome is caused by mutations in COL2A1, COL11A1, and COL11A2 genes. ${ }^{3}$ A recessive form of Stickler syndrome with COL9A1 gene mutation has been described. ${ }^{4,5}$ Ocular features of Stickler syndrome include myopia, glaucoma, and retinal detachment (RD). ${ }^{4-7}$ Patients with type 1 Stickler syndrome are at a high risk of visual loss from rhegmatogenous retinal detachment (RRD), particularly from a giant retinal tear that often occurs before 30 years of age. ${ }^{8-10}$

The presence of multiple breaks and liquefied abnormal vitreous complicates the management of Stickler syndrome patients. ${ }^{11,12}$ Previous literature has shown that RRD in Stickler syndrome is complex and consistently difficult to manage, with a lower success rate of repair compared with the typical degenerative RRD in non-Stickler
Correspondence: Saba Al-Rashaed Vitreoretinal Department, King Khaled Eye Specialist Hospital, PO Box 7|91, Riyadh I 1462, Kingdom of Saudi Arabia Tel +966 | 482 I 234

Fax +966 I 482 I 234 ext 3727

Email srashaed@kkesh.med.sa (c) (i) (9) 2016 Alshahrani et al. This work is published by Dove Medical Press Limited, and licensed under Creative Commons Attribution - Non Commercial (unported, v3.0) Lic ${ }_{\text {NC }}$ Lice. The full terms of the License are available at http://creativecommons.org/licenses/by-nd/3.0/. Non-commercial uses of the work are permitted without any further permisio how to request permission may be found at: http://www.dovepress.com/permissions.php 
patients. ${ }^{7,13,14}$ Two studies recommended that primary vitrectomy should be considered the surgery of choice for RRD in Stickler syndrome patients. ${ }^{7,13}$

The issue of prophylaxis laser or cryotherapy in Stickler patients remains controversial. For example, a retrospective analysis concluded that prophylactic cryotherapy can reduce the risk of $\mathrm{RD}$ and eliminate the risk of bilateral detachments. ${ }^{14} \mathrm{~A}$ review of prophylactic retinopexy was inconclusive regarding prevention of RRD. ${ }^{15}$

King Khaled Eye Specialist Hospital (KKESH) is a major referral center throughout the Kingdom of Saudi Arabia for patients with RRD with Stickler syndrome. Hence, a large number of cases and long follow-up allowed us to perform a study that evaluated the clinical presentation, management, and outcomes of RRD in patients with Stickler syndrome. Additionally, we evaluated the value of laser prophylaxis.

\section{Patients and methods}

In this observational case series, we performed a retrospective chart review of patients with Stickler syndrome who presented with RRD at KKESH from 1997 to 2011. Prior to data collection, the institutional review board at KKESH approved this study. The institutional review board did not require patient consent be obtained because this was a retrospective study. This study adhered to the tenets of the Declaration of Helsinki.

Data were collected on systemic and ocular manifestations, age, sex, past medical and ocular history, family history and history of RD in the fellow eye. Ocular data were collected for visual acuity (VA), intraocular pressure, strabismus, cataract, refractive error, details of the $\mathrm{RD}$, location and the number of breaks, the presence of posterior vitreous detachment, the presence of proliferative vitreoretinopathy (PVR), modalities of treatment, intra- and postoperative complications, causes of recurrent $R R D$, visual and anatomic outcomes. The data were tabulated in an electronic spreadsheet. Descriptive statistics and statistical analysis was performed to identify the predictive variables for the final visual and anatomical outcomes. A subgroup of eyes that received prophylactic laser was analyzed to better understand the role of prophylaxis.

The association between two categorical variables was investigated using chi-square test or Fisher's exact test, as appropriate. A $P$-value less than 0.05 indicated statistical significance. Odds ratios (OR) and their corresponding 95\% confidence intervals (CIs) were calculated to estimate the relative risk. A CI that did not include a value of 1.0 indicated statistical significance. Stepwise logistic regression analysis was performed to identify variables that influenced the achievement of final VA of 20/200 or better as well as the final anatomic outcome after adjustment for all other confounding variables.

\section{Results}

The study cohort comprised 62 patients (70 eyes) with Stickler syndrome who presented with RRD. Thirty-seven patients (60\%) were male and $25(40 \%)$ were female. The demographic data, ocular and systemic manifestations for Stickler syndrome are summarized in Table 1. The median age for the cohort was 11.5 years (range: 3-45 years). Five eyes had inoperable RRD at the time of primary vitrectomy. These patients had cataract and extensive synechia and after removal, the retina could not be reattached because it was fibrotic. At presentation, 22 (31.4\%) eyes had a giant tear, six $(8.6 \%)$ eyes had a horseshoe break, single breaks were present in seven $(10.0 \%)$ eyes, multiple breaks in $35(50 \%)$ eyes, and macular hole in two $(2.85 \%)$ eyes. All eyes in this study presented with breaks associated with condensed vitreous veils; 53 eyes (75.7\%) had lattice changes; and 34 (48.6\%) had lattice-associated breaks.

All vitrectomies were performed using the 20- and 23-gauge systems $\left(\right.$ Ocutome $^{\circledR}{ }^{\circledR}$, Accurus $^{\circledR}$, and Constellation ${ }^{\circledR}$

Table I Demographics, ocular and systemic manifestations at presentation of Stickler syndrome patients with rhegmatogenous retinal detachment

\begin{tabular}{lll}
\hline Manifestation at presentation & Number & Percentage \\
\hline Bilateral eye involvement & 8 & 12.9 \\
Right eye involvement & 25 & 40.3 \\
Left eye affected & 29 & 46.8 \\
Positive family history & 14 & 22.6 \\
History of RD in fellow eye & 22 & 35.4 \\
Visual acuity $>$ 20/200 & 13 & 19 \\
Visual acuity $<20 / 200$ & 57 & 81 \\
Macula off & 65 & 92.9 \\
Macula on & 5 & 7.1 \\
Total RD & 44 & 62.9 \\
Proliferative vitreoretinopathy & 35 & 50 \\
Posterior vitreous detachment & 29 & 41.4 \\
Giant tear & 22 & 31.4 \\
Optically empty vitreous & 70 & 100 \\
Pre-senile cataract & 27 & 38.6 \\
Myopia & 63 & 90.0 \\
Lattice degeneration & 53 & 75.7 \\
High arched palate & 5 & 7.14 \\
Micrognathia & 7 & 10 \\
Deafness & 5 & 7.14 \\
Joint hypermobility & 2 & 2.86 \\
Flat face & 6 & 8.57 \\
Tall stature & 2 & 2.86 \\
\hline Note: The stdy popation conssed & 37 &
\end{tabular}

Note: The study population consisted of 37 males $(60 \%)$ and 24 females (40\%). Abbreviation: RD, retinal detachment. 
units (Alcon, Inc., Ft Worth, TX, USA). Vitreous cortex was removed in most cases up to the peripheral retina with a widefield system (BIOM, Oculus Surgical, Inc., Port St Lucie, FL, USA) and VOLK (Volk Optical Inc., Mentor, $\mathrm{OH}, \mathrm{USA}$ ) lenses. In cases where peeling could not be performed, a $360^{\circ}$ scleral buckle, either a type 240 band or 41 band was used based on surgeon preference (Labtician Ophthalmics Inc., Oakville, ON, Canada and Dutch Ophthalmic Research Center, Zuidland, the Netherlands). Scleral buckling (SB) was used to support peripheral pathologies (eg, lattice degeneration, peripheral breaks) and the vitreous base if vitreous cortex could not be completely removed. The aim of SB was to decrease the recurrence rate. Recently, we began using triamcinolone to stain the posterior vitreous for good visualization. Endolaser for vitrectomy and cryotherapy were performed in cases that only underwent an SB procedure. Silicone oil $(5,000 \mathrm{cSt})$ tamponade was also performed (Geuder AG, Heidelberg, Germany; and Dutch Ophthalmic Research Center, Zuidland, the Netherlands).

Ten eyes underwent SB surgery (360 band with 70 sleeve) with cryotherapy with a primary success rate of $60 \%$. Seven eyes underwent vitrectomy only with a primary success rate of $57.1 \%$ (Table 2). Forty-eight eyes were treated with combined scleral buckle and pars plana vitrectomy (PPV), with a primary success rate of $75 \%$ (Table 2 ). Due to cataractous changes, lens removal was performed during the primary procedure in $33(47.1 \%$ ) eyes (Table 2$)$. Lens removal was performed by pars plana lensectomy or lens aspiration without intraocular lens implantation. Intraoperatively, iatrogenic breaks occurred in 20 (28\%) eyes and five (7.1\%) eyes were deemed inoperable (surgery failed). Postoperative complications included cataract in $18(25.7 \%)$ eyes, recurrent RD in 19 (27.1\%) eyes, PVR in ten (14.3\%) eyes, choroidal hemorrhage in one (1.4\%) eye, band keratopathy in six (8.57\%) eyes, epiretinal membrane in five $(7.14 \%)$ eyes, and raised intraocular pressure in 19 (27.1\%) eyes. PVR caused recurrent $\mathrm{RD}$ in ten (52\%) eyes; new breaks were noted in five (26\%) eyes and previous breaks opened in four $(21.1 \%)$ eyes.
The average time for postoperative RD after a primary procedure was 2.6 months (range: 2 weeks to 2 years). Average time to postoperative RD was 6.4 months following SB, 3 weeks following PPV, and 3.04 months following combined SB and PPV.

The average duration of postoperative follow-up was $3.8 \pm 2.7$ years (range: 1 month to 14 years; median 3.0 years). At the last follow-up, Snellen VA had not changed in 20 (28.57\%) eyes, increased more than two lines in 45 (62.29\%) eyes, and decreased by two or more lines in five (7.14\%) eyes. The number of eyes with less than 20/200 vision decreased statistically significantly from $57(81 \%)$ eyes at presentation to $26(37 \%)$ eyes at last follow-up $(P<0.001)$. The number of eyes with VA of 20/40 or better increased statistically significantly from none at presentation to eleven (16\%) eyes at last follow-up $(P=0.001)$.

Poor vision postoperatively was due to diseased retina in $25(35.8 \%)$ eyes, amblyopia in 19 (27.1\%) eyes, undetermined in nine $(12.9 \%)$ eyes, detached retina in nine $(12.9 \%)$ eyes, cataract in eight $(11.4 \%)$ eyes, and other in two $(2.9 \%)$ eyes.

Univariate analysis indicated that there was a statistically significant association with final VA of 20/200 or better with: VA at presentation $(P=0.029)$; and negative association to total $\mathrm{RD}(P \leq 0.001)$, cataract at presentation $(P=0.023)$, PVR $(P=0.001)$, and SB $(P=0.010)$. Posterior vitreous detachment, the degree of myopia, strabismus, the type and number of breaks, and the type of surgery performed were not significantly associated with final visual outcome. The presence of PVR was the only statistically significant association with poor VA (worse than 20/200) $(P<0.001)$.

Postoperatively, nine eyes were not anatomically attached. Five eyes were deemed inoperable during surgery and four eyes after initial and subsequent surgeries. If PVR was present, the OR increased to 8.5 , and if there were more than six breaks, the OR was 3.13 (Table 3). The variables that influenced a final postoperative vision of $20 / 20$ or better

Table 2 Association between the type of primary procedure for retinal detachment repair and success rate, visual outcome, and complications in eyes of Stickler syndrome patients

\begin{tabular}{lllllll}
\hline Surgery & $\begin{array}{l}\text { Number of eyes, } \\
(\%)^{\mathbf{a}}\end{array}$ & $\begin{array}{l}\text { Recurrent } \\
\mathbf{R D}, \mathbf{n}(\%)\end{array}$ & $\begin{array}{l}\text { Success with single } \\
\text { surgery, } \mathbf{n}(\%)\end{array}$ & $\begin{array}{l}\text { PVR, } \\
\mathbf{n}(\%)\end{array}$ & $\begin{array}{l}\text { Final success } \\
\text { rate, } \mathbf{n}(\%)^{\mathbf{b}}\end{array}$ & $\begin{array}{l}\mathbf{2 0 / 2 0 0} \text { or better } \\
\text { final vision, } \mathbf{n}(\%)\end{array}$ \\
\hline SB & $10(15.4)$ & $4(40)$ & $6(60)$ & 0 & $10(100)$ & $10(100)$ \\
PPV & $7(10.8)$ & $3(42.9)$ & $4(57.1)$ & $2(28.6)$ & $6(85.7)$ & $2(28.6)$ \\
SB + PPV & $48(73.8)$ & $12(25)$ & $36(75)$ & $8(16.6)$ & $45(93.8)$ & $31(64.6)$ \\
Overall & $65(100)$ & $19(27.1)$ & $46(70.8)$ & $10(15.4)$ & $61(93.8)$ & $44(67.7)$ \\
\hline
\end{tabular}

Notes: aFive eyes deemed inoperable at the time of surgery were excluded. ' $F$ Final success rater after primary and secondary procedures. Abbreviations: PVR, proliferative vitreoretinopathy; PPV, pars plana vitrectomy; RD, retinal detachment; SB, scleral buckling. 
Table 3 Association between postoperative retinal detachment after all surgical procedures with risk factor at presentation for Stickler syndrome patients

\begin{tabular}{llllll}
\hline Risk factors & Number & Retina detached (nine eyes) & Odds ratio & $\mathbf{9 5 \%} \mathbf{C l}$ & $\mathbf{P}$-value* \\
\hline Presence of PVD & 29 & $3(10.3 \%)$ & 0.83 & $0.12-4.73$ & 0.999 \\
Presence of PVR & 35 & $7(20.0 \%)$ & 8.5 & $0.97-394.1$ & 0.055 \\
Giant retinal tears & 22 & $3(13.6 \%)$ & 1.36 & $0.19-7.80$ & 0.700 \\
Hx of previous laser treatment & 16 & $1(6.3 \%)$ & 0.45 & $0.01-4.01$ & 0.672 \\
PPV surgery & 7 & $2(28.6 \%)$ & 3.80 & $0.29-29.93$ & 0.180 \\
Scleral buckle & 10 & $0(0.0 \%)$ & 0.0 & NA & 0.591 \\
Scleral buckle + PPV & 48 & $3(6.3 \%)$ & 0.23 & $0.03-1.34$ & 0.098 \\
\hline
\end{tabular}

Note: $* P<0.05$ was statistically significant.

Abbreviations: $\mathrm{Cl}$, confidence interval; $\mathrm{Hx}$, history; NA, not applicable; PVD, posterior vitreous detachment; PVR, proliferative vitreoretinopathy; PPV, pars plana vitrectomy.

included: $(\mathrm{OR}=0.174 ; 95 \% \mathrm{CI}=0.06-0.55)$ and cataract $(\mathrm{OR}=0.328 ; 95 \% \mathrm{CI}=0.11-1.01)$ were negatively associated with a final VA of 20/200 or better.

In the entire cohort, $44(62.8 \%)$ eyes had undergone prior prophylactic laser treatment. Sixteen of $44(36.3 \%)$ eyes developed RD after prophylactic laser treatment. The mean duration between prophylactic laser treatment and RD was 27.5 months (range: 1 week to 10 years). There were no statistically significant differences in baseline characteristics or final outcome between eyes that received prophylactic laser compared with eyes that did not.

\section{Discussion}

Stickler syndrome is an inherited connective tissue disease that commonly presents with RRD. We found that $22.6 \%$ of the patients had a positive family history of RRD supporting heritability of this type of $\mathrm{RD}$. Due to the retrospective nature of our study, the lack of a genetic workup and family evaluation, we were unable to analyze the pattern of inheritance in the study cohort.

There are very few published studies from other countries that document the characteristics and the outcomes of therapy for Stickler syndrome patients with RRD., ${ }^{73}$ Table 4 presents a comparison between our study and three previous studies. ${ }^{7,13,14}$ In our study, the final success rate for retinal reattachment was $93.8 \%$ and the success rate of primary surgery was $70.8 \%$, which is higher than previous studies. ${ }^{7,13}$ However, $70.8 \%$ success is much lower than the $90 \%-95 \%$ success rate reported for primary surgery of typical RRD repair for non-Stickler patients. ${ }^{14}$ Several factors might have caused the lower success rate in RRD in Stickler syndrome. These include a much younger age at presentation (median age 11.5 years in our study) with an anomalous vitreoretinal interface, the presence of giant tears in many eyes ( $31.4 \%$ in our study), the presence of multiple retinal breaks in many eyes (50\% in our series), and the high prevalence of PVR (50\% of eyes in our study). Additionally, the majority (62.9\%) of eyes had total RD and there was macular involvement in $92.9 \%$ of eyes. All these variables make surgical intervention more challenging regardless of the type of the procedure and advances in surgical techniques. Table 4 indicates that the primary anatomic success rate has changed little from 1985 (almost $60 \%)$ to date $(\sim 70 \%)$.

Table 4 Comparison between the current study and two previous studies on Stickler syndrome

\begin{tabular}{|c|c|c|c|c|c|c|c|c|c|}
\hline Study & $\begin{array}{l}\text { Number } \\
\text { of eyes }\end{array}$ & $\begin{array}{l}\text { Age } \\
\text { (years) }\end{array}$ & $\begin{array}{l}\text { GRT, } \\
\text { n (\%) }\end{array}$ & $\begin{array}{l}\text { Multiple retinal } \\
\text { tears, } \mathbf{n}(\%)\end{array}$ & $\begin{array}{l}\text { PVR at } \\
\text { presentation, } \\
\text { n (\%) }\end{array}$ & Final detached retina & $\begin{array}{l}\text { Primary } \\
\text { success } \\
\text { rate }(\%)\end{array}$ & $\begin{array}{l}\text { Overall } \\
\text { success } \\
\text { rate (\%) }\end{array}$ & $\begin{array}{l}\text { VA } 20 / 200 \\
\text { or better, } \\
n(\%)\end{array}$ \\
\hline $\begin{array}{l}\text { Present } \\
\text { study (20I2) }\end{array}$ & 70 & $\begin{array}{l}\text { Range: } 3-45 \\
\text { Mean: } 13\end{array}$ & $22(31.4)$ & $35(50)$ & $35(50)$ & $\begin{array}{l}\text { Nine eyes (five inoperable } \\
\text { from the beginning of the } \\
\text { study) }\end{array}$ & 70.8 & 93.8 & $44(67.7)$ \\
\hline $\begin{array}{l}\text { Billington } \\
\text { et } \mathrm{al}^{7}\end{array}$ & 42 & $\begin{array}{l}\text { Range: } 4-35 \\
\text { Mean: } 25\end{array}$ & $9(25)$ & I (47.2) & $10(27.8)$ & $\begin{array}{l}15 \text { eyes ( } 6 \text { inoperable } \\
\text { from the beginning of the } \\
\text { study) }\end{array}$ & 59.1 & 75 & $\begin{array}{l}\text { Not } \\
\text { mentioned }\end{array}$ \\
\hline $\begin{array}{l}\text { Abeysiri } \\
\text { et } \mathrm{al}^{13}\end{array}$ & 30 & $\begin{array}{l}\text { Range: } 5-5 \text { I } \\
\text { Mean: } 20.67\end{array}$ & $4(13.3)$ & $15(50)$ & 14 (46.6) & $\begin{array}{l}\text { Eight eyes (six inoperable } \\
\text { from the beginning of the } \\
\text { study) }\end{array}$ & 78.57 & 93.3 & $22(73.3)$ \\
\hline
\end{tabular}

Abbreviations: GRT, giant retinal tear; PVR, proliferative vitreoretinopathy; VA, visual acuity. 
A relatively poor primary anatomic success rate was also noted in our study regardless of the type of procedure performed, although the best success was noted in eyes that underwent PPV in combination with an SB procedure (Table 2). Vitreous cortex removal is one of the challenging steps in these cases. However, we could remove vitreous cortex in most cases out to the peripheral retina using a widefield system (BIOM) and VOLK lenses with triamcinolone acetonide for cortical staining. This relative success can be explained by the alleviation of tractional effects of the anomalous vitreous on the retina by PPV and the closure of posterior and anterior retinal breaks. This may be augmented by the SB effect, which addresses the anterior tractional forces and retinal breaks, particularly breaks located in the vitreous base supported by the buckle. Although clinically relevant, the association between the type of surgery and the final anatomic outcome was not statistically significant in our study $(P>0.05)$. Only silicone oil tamponade was statistically significantly associated to the final anatomic outcome, with a protective $\mathrm{OR}$ for final $\mathrm{RD}$ of $0.11(P=0.027)$. All the other factors, including the presence of posterior vitreous detachment, PVR, number of breaks, macular hole, giant retinal tears, history of prophylactic laser, type of surgery, and lens removal at the time of surgery, were not significant predictors of the final anatomic outcome. For example, our study showed that the prevalence of recurrent RRD was $21 \%$ when silicone oil was used as intraocular tamponade during surgery compared with $47 \%$ with intraocular perfluoropropane (C3F8) gas. This finding may be due to the complexity of RRD in Stickler syndrome. As mentioned earlier, silicone oil may be advantageous compared to gas tamponade in these young patients with multiple and large retinal breaks that are often complicated with PVR. The beneficial effect of silicone oil has been previously reported. ${ }^{16}$ Therefore, our data, as well as that from previous studies, suggest that a combination procedure of PPV, scleral buckle, and silicone oil injection may be the procedure of choice in eyes with RRD in patients with Stickler syndrome.

VA at the final postoperative visit remained stable (28.57\%) or improved (64.29\%) compared with baseline in the majority of eyes. The prevalence of poor vision (less than $20 / 200$ ) decreased significantly from $81 \%$ at presentation to $37 \%$ at last follow-up. However, these visual outcomes indicate that a significant number of eyes were still legally blind. The cause may be multifactorial. The referral system at KKESH may be one contributing factor due to the sheer volume of patients. Other, disease-related variables may also be important. For example, a large proportion of eyes had macular involvement with $\mathrm{RD}$ as well as complete $\mathrm{RD}$ and PVR. These factors may impact the final visual outcome. Other confounding factors are presentation at a very young age (pediatric patients), which may result in delays in the recognition of symptoms and diagnostic delay, more advanced presentations (as shown in our study), and amblyopia. In our study, amblyopia was present in $27.1 \%$ of eyes at last follow-up. Other causes of poor visual outcome may include band keratopathy and cataract as noted in our study. Although many of these factors were found to be associated with the final visual outcome with univariate analysis, the only two variables that continued to be significant during stepwise logistic regression analysis were PVR and cataract. Both of these variables had a negative effect on visual outcome. This outcome could be due to the chronic nature of the disease and the difficulties encountered during surgical repair.

We also compared the visual and anatomic outcomes between eyes that did or did not undergo laser prophylaxis prior to the onset of RD. Interestingly, the two groups of eyes did not show any significant differences in either their baseline characteristics or the final outcomes. For example, the achievement of $20 / 200$ or better vision occurred in $68.8 \%$ in eyes that underwent laser prophylaxis and $61.1 \%$ of eyes that did not undergo prophylaxis. Similarly, reattachment rates were $93 \%$ in eyes that underwent prophylaxis versus $87 \%$ in eyes that did not undergo prophylaxis. Of note, the characteristics of RD at baseline were not significantly different between these two groups of eyes, indicating that prophylactic laser does not appear to be protective for the severity of RD once it develops. Our finding of $36.3 \%$ eyes with RD despite prior laser prophylaxis questions the benefit of this intervention in the fellow eyes of patients with Stickler syndrome and RRD. The interval of RRD after laser prophylaxis in our study ranged from 1 week to 10 years. In fact, two eyes developed RRD within 2 weeks after prophylactic laser application. The causative breaks in these eyes were at or adjacent to the laser-treated areas, supporting Billington et $\mathrm{al}^{7}$ findings that prophylactic laser treatment precipitated posterior vitreous detachment and retinal breaks adjacent to the treated areas. These findings contradict Ang et al ${ }^{15}$ who suggested that $360^{\circ}$ prophylactic transconjunctival cryotherapy virtually eliminated RRD in eyes with Stickler syndrome type 1 including patient with previous RD in the fellow eye. However, a more recent systematic review by Carroll et a ${ }^{17}{ }^{17}$ concluded that data from studies of prophylactic retinopexy to date do not permit the generation of a reliable estimate of their effectiveness compared with no prophylaxis and that the benefit remains uncertain. They also noted a high 
risk of bias in studies of prophylactic retinopexy due to their retrospective nature and lack of comparability between the intervention and control groups, especially with respect to confounding factors such as age and duration of follow-up. ${ }^{15}$ Our outcome that over one-third of the eyes continued to develop RRD despite prior prophylactic retinopexy concurs with Carroll et al ${ }^{17}$ conclusions.

\section{Conclusion}

This retrospective study confirms the findings of previous reports indicating that $\mathrm{RRD}$ in Stickler syndrome is a complex and difficult entity to manage despite the improvement in surgical techniques and instrumentation. However, a good proportion of eyes may recover reasonable vision, especially those without PVR or cataract at presentation. Based on our results, it appears that vitrectomy combined with scleral buckle and silicone oil tamponade offers the best outcome and should be considered the primary procedure of choice. Our study also suggests that the role of prophylactic retinopexy in these eyes remains controversial. For eyes that undergo prophylaxis to decrease risk, close follow-up and monitoring is required as a number of eyes still seem to develop RRD.

\section{Disclosure}

The authors report no conflicts of interest in this work.

\section{References}

1. Stickler GB, Belau PG, Farrell FJ, et al. Hereditary progressive arthroophthalmopathy. Mayo Clin Proc. 1965;40:433-455.

2. Snead MP. Hereditary vitroretinopathy. Eye (Lond). 1996;10(Pt 6): 653-663.

3. Vandenberg P. Molecular basis of heritable connective tissue disease. Biochem Med Metab Biol. 1993;49(1):1-12.
4. Ahmad NN, McDonald-McGinn DM, Dixon P, Zackai EH, Tasman WS. PCR assay confirms diagnosis in syndrome with variably expressed phenotype: mutation detection in Stickler syndrome. J Med Genet. 1996; 33(8):678-681.

5. Van Camp G, Snoeckx RL, Hilgert N, et al. New autosomal recessive form of Stickler syndrome is caused by a mutation in COL9A1 gene. Am J Hum Genet. 2006;79(3):449-457.

6. Richard AJ, Martin S, Yates JRW, et al. COL2A1 exon 2 mutations: relevance to the Stickler and Wagoner syndrome. Br J Ophthalmol. 2000; 84(4):364-371.

7. Billington BM, Leaver PK, McLeod D. Management of the retinal detachment in the Wagner-Stickler syndrome. Trans Ophthalmol Soc UK. 1985;104(Pt 8):875-879.

8. Stickler GB, Hughes W, Houchin P. Clinical features of hereditary progressive arthro-ophthalmopathy (Stickler syndrome): a survey. Genet Med. 2001;3(3):192-196.

9. Richard AJ, Snead MP. The influence of pre-mRNA splicing on phenotypic modification in Stickler syndrome and other type II collagenopathies. Eye (Lond). 2008;22(10):1243-1250.

10. Donoso LA, Edwards AO, Frost AT, et al. Identification of a stop codon mutation in exon 2 of the collagen 2A1 gene in a large Stickler syndrome family. Am J Ophthalmol. 2002;134(5):720-727.

11. Hagler WS, Crosswell HH Jr. Radial perivascular chorioretinal degeneration and retinal detachments. Trans Am Acad Ophthalmol Otolaryngol. 1968;72(2):203-216.

12. Hirose T, Lee KY, Schepens CL. Wagners hereditary vitreoretinal degeneration and retinal detachment. Arch Ophthalmol. 1973;89(3): 176-185.

13. Abeysiri $\mathrm{P}$, Bunce $\mathrm{C}$, da Cruz L. Outcomes of surgery for retinal detachment in patients with Stickler syndrome: a comparison of two sequential 20-year cohorts. Graefes Arch Clin Exp Ophthalmol. 2007;245(11):1633-1638.

14. Schaal S, Sherman MP, Barr CC, Kaplan HJ. Primary retinal detachment repair: comparison of 1-year outcomes of four surgical techniques. Retina. 2011;31(8):1500-1504.

15. Ang A, Poulson AV, Goodburn SF, Richards AJ, Scott JD, Snead MP. Retinal detachment and prophylaxis in type I Stickler syndrome. Ophthalmology. 2008;115(1):164-168.

16. Pagot-Mathis V, Benouaich X, Mathis A, Rico-Lattes I, Dumoulin A. Management of complicated retinal detachment using a heavy silicone oil as temporary tamponade. J Fr Ophthalmol. 2006;29(2):137-145.

17. Carroll C, Papaioannou D, Rees A, Kaltenthaler E. The clinical effectiveness and safety of prophylactic retinal interventions to reduce the risk of retinal detachment and subsequent vision loss in adults and children with Stickler syndrome: a systematic review. Health Technol Assess. 2001;15(16):1-62.
Clinical Ophthalmology

\section{Publish your work in this journal}

Clinical Ophthalmology is an international, peer-reviewed journal covering all subspecialties within ophthalmology. Key topics include: Optometry; Visual science; Pharmacology and drug therapy in eye diseases; Basic Sciences; Primary and Secondary eye care; Patient Safety and Quality of Care Improvements. This journal is indexed on Submit your manuscript here: http://www.dovepress.com/clinical-ophthalmology-journal

\section{Dovepress}

PubMed Central and CAS, and is the official journal of The Society of Clinical Ophthalmology (SCO). The manuscript management system is completely online and includes a very quick and fair peer-review system, which is all easy to use. Visit http://www.dovepress.com/ testimonials.php to read real quotes from published authors. 